\title{
Valor e concorrência em Marx e os vários equívocos da crítica de Schumpeter
}

Francisco Paulo Cipolla ${ }^{1}$

Resumo: Este artigo procura mostrar que a reverência à teoria de Marx por parte dos teóricos neoclássicos se apresenta, na verdade, como ocasião para críticas de motivação ideológica e até mesmo para distorções aberrantes. Schumpeter, muitas vezes tomado como referência bibliográfica básica para o "entendimento" das incoerências da teoria do valor e da concorrência de Marx, é um exemplo disso. Este artigo argumenta que as críticas de Schumpeter oscilam entre a mera reafirmação da teoria neoclássica e as cirurgias teóricas as mais aberrantes, tais como a substituição da tendência decrescente da taxa de lucro pela eliminação do lucro econômico neoclássico. $\mathrm{O}$ artigo conclui que a explicitação, desenvolvimento e aplicação empírica da teoria de Marx só pode ser obra dos marxistas. Cabe a eles, no entanto, a tarefa de fazer esse trabalho melhor do que aqueles que a desfiguram sistematicamente.

Palavras-chave: Marx; Schumpeter; teoria do valor e da concorrência.

\section{Marx's theory of value and competition and Schumpeter's errors}

\begin{abstract}
This article argues that references to Marx's theory made by neoclassical economists are often used as an occasion for ideological bashing and sometimes even result in grotesque misrepresentations of that theory.
\end{abstract}

1 Universidade Federal do Paraná, cipolla@ufpr.br. 
Schumpeter is one case in point. His critical interpretation of the "shortcomings" of the theory of value and competition, which is often viewed as a standard critique, is in fact a repetition of neoclassical theory, on the one hand, and a distortion of Marx's own thought on the other. The article concludes that it is up to marxists to make the work of developing and applying their own theory. However, they have to do it in a way so as not to deface Marx's theory as his critics have persistently done.

Keywords: Marx; Schumpeter; theory of value and competition.

JEL: B3

\section{Introdução}

A luta ideológica contra a teoria social de Marx levada a cabo pelos principais expoentes da teoria econômica burguesa oscila da censura absoluta às caricaturas mais grotescas. $\mathrm{O}$ exemplo de censura pode ser colhido de Keynes (1936) no qual a primeira das duas referências diz respeito à sobrevivência do princípio da demanda efetiva "nos submundos de Karl Marx, Silvio Gesell ou Major Douglas" (:32) e a segunda arremata dizendo que ele acredita que o "futuro aprenderá mais do espírito de Gesell do que de Marx" (:355); ou pode ser colhida mais recentemente de Mankiw (1992) que também através de duas referências manda Marx às traças. A primeira aparece no item Distributing National Income to the Factors no qual ele diz que Karl Marx "gastou muito tempo tentando explicar as rendas do capital e do trabalho" e que a "filosofia política do comunismo baseava-se em parte na sua - hoje em dia - desacreditada teoria" (:49). E fecha mais à frente sua reverência afirmando que hoje se estuda a teoria do crescimento de Solow e não de Marx porque a predição de Marx de que a taxa de retorno do capital iria cair ao longo do tempo levando a crises econômicas e políticas não se verificou (:106).

Samuelson e Nordhaus (1985), por outro lado apresentam uma seção de 14 páginas sob a rubrica Marxismo e Sistemas Econômicos Alternativos, depois de uma referência ao nascimento da Union of Radical Political Economics nos Estados Unidos. Na apresentação da teoria de Marx confundem trabalho com força de trabalho ${ }^{2}$ e chegam a dizer que Marx percebeu que preços não coincidiam com valor porque os capitalistas recebiam uma renda que excedia os custos com a força de trabalho, ou seja, a mais valia! ${ }^{3}$ Em seguida afirmam que as profecias de Marx

2 "...what gives value to a commodity is the total amount of labor power used to produce it". Aqui eles querem dizer "total amount of labor". (Samuelson \& Nordhaus 1985:768)

3 "Marx realized that market prices under competitive capitalism would not necessarily equal labor values. Why not? Because capitalists receive an excess in revenue over labor costs - a surplus value". (idem:768) 
não se realizaram, pois os salários reais dos trabalhadores assim como sua participação na renda nacional aumentaram; a jornada de trabalho diminuiu; a taxa de lucro não declinou e o poder político dos trabalhadores aumentou por meio das urnas e não das armas. Ademais, argumentam: como poderia ter Marx previsto o aparecimento da Teoria Geral de Keynes e sua aplicação como instrumento de redução do desemprego e garantia de uma estabilidade econômica jamais vista anteriormente? E concluem: "A história não foi generosa com as profecias de Marx. Como sempre acontece, a história raramente executa o script elaborado por meros mortais" (:769).$^{4}$

O caso de Schumpeter é mais grave ainda. Sua apresentação de Marx é na verdade uma defesa escancarada da teoria neoclássica. Para tal, se vale de dois expedientes: piora consideravelmente a exposição realizada pelo próprio Marx $^{5}$ e julga a teoria deste último utilizando o instrumental da teoria neoclássica. Por isso sua apresentação da teoria de Marx merece uma analise mais detalhada.

\section{Marx face a Ricardo}

A primeira falha importante de Schumpeter é considerar as teorias do valor de Ricardo e Marx como iguais: valores são proporcionais às quantidades de trabalho desde que representem a quantidade de "trabalho socialmente necessário". Schumpeter esquece que a noção de trabalho socialmente necessário é especificamente de Marx. Em seguida iguala as dificuldades encontradas pelos dois pensadores como se Marx não tivesse resolvido o problema da diferença entre preço e valor. Essa diferença aparece nos cálculos de Ricardo porque ele toma a razão entre lucro e salário como sendo a taxa de lucro. Em seguida aplica essa taxa de lucro ao capital fixo o que faz surgirem lucros que não têm nenhum respaldo em trabalho e, portanto, uma diferença entre preço e o valor em trabalho. A taxa de lucro apresentada por Ricardo na seção IV do primeiro capítulo dos Princípios não poderia ser 10\% mas 6,45\%! Aplicando essa taxa de lucro o valor total em trabalho iguala 11000 e o preço total a mesma quantia! ${ }^{6}$

Schumpeter ignora a solução em agregado para a igualdade entre preço e valor. Ao contrário, concentrando-se somente nas discrepâncias desagregadas afirma que a igualdade entre preço e valor só é possível

4 Artigo neste volume (Paul Cooney) explora precisamente a atualidade das tendências apontadas por Marx como partes intrínsecas do modo de funcionamento do capitalismo.

5 É nitidamente o caso a sua exposição da teoria da mais valia.

6 Câmara, Cordeiro \& Cipolla (mimeo, UFPR 200o). 
em equilíbrio e concorrência perfeita. ${ }^{7} \mathrm{E}$ ademais somente se o trabalho for o único fator de produção. E mais: se todo trabalho for de mesma espécie, isto é, trabalho homogêneo. Mas nesse caso, diz ele, em êxtase, a teoria neoclássica também obtém a igualdade entre quantidade de trabalho e valor. Mas isso é plena tautologia! Tendo apenas o fator trabalho não há capitalismo e obviamente o salário é igual a todo o produto. Essa é a natureza do argumento: elimina-se o objeto de estudo e a teoria neoclássica explica o problema posto pelo objeto de estudo!

Apesar da teoria do valor de Ricardo constituir o ponto de partida da teoria do valor de Marx, esta última se diferencia daquela em diversos aspectos fundamentais: a distinção entre trabalho concreto e trabalho abstrato; a distinção entre trabalho socialmente necessário e trabalho individual; a distinção entre trabalho e força de trabalho $^{8}$ são algumas das mais importantes contribuições que diferenciam Marx de Ricardo.

As suas visões divergem também quanto aos efeitos da mecanização sobre o desemprego; quanto à relação entre taxa de mais valia e taxa de lucro. Por fim suas teorias divergem profundamente sobre a questão das crises: enquanto Ricardo é partidário da lei de Say, Marx argumenta que a metamorfose da mercadoria entre venda e compra sugere a possibilidade de crise generalizada de super-produção e, a níveis mais concretos de análise, a inevitabilidade dessas crises.

Schumpeter confunde as seções IV e V do primeiro capítulo do livro de Ricardo. Confunde as diferenças entre quantidade de trabalho e preço que se originam das diferentes proporções de capital fixo no capital total (seção IV) com as diferenças que se originam dos diferentes períodos de rotação do capital (seção V). Na seção IV Ricardo não poderia ter tomado o produto líquido para efetuar o cálculo da taxa de lucro. Deveria, isto sim, ter calculado a razão entre o lucro e o capital total investido. Da forma como procedeu, Ricardo termina por utilizar a taxa de mais valia como taxa de lucro a ser aplicada sobre o capital fixo. Ao assim fazer, ele obtém lucros que não advém do trabalho excedente, fato que gera uma discrepância entre valor e preço.

7 É interessante observar que a concorrência perfeita requer características tais que são a antítese da concorrência, entendida como competição. Essas características são: ausência de poder de monopólio; curvas de demanda e oferta que para os produtores individuais se apresentam como curvas horizontais; produção individual negligenciável em relação ao agregado; comportamento tomador de preço com relação aos preços estabelecidos publicamente; lucro zero e igualdade de rentabilidade em todos os setores da economia; preços iguais ao custo marginal; rentabilidade dos fatores iguais ao valor do produto marginal; Pareto-ótimo das alocações de mercado. As condições estruturais para a concorrência perfeita são: grande número de produtores; liberdade perfeita de entrada e saída; plena informação e custos negligenciáveis de pesquisa ( search costs); homogeneidade e divisibilidade de produto; ausência de colusão; ausência de externalidades e de retornos crescentes de escala (Roberts 1987).

8 A respeito das diferenças entre Marx e Ricardo ver Giussani (1983). 
Apesar de ter uma visão acurada do problema tal como se apresenta para Ricardo, Schumpeter não apresenta a solução desenvolvida por Marx, limitando-se a dizer que este último dedicou ao problema centenas de páginas (:25) o que não dá ao trabalho de Marx nenhum status especial já que é difícil encontrar um tema em relação ao qual Marx tenha dedicado um número pequeno de páginas. Somente mais à frente Schumpeter volta a se referir ao problema da equalização das taxas de lucro e dos desvios que ela produz entre valores e preços (:29).

\section{A teoria do valor e do dinheiro}

Como vimos, o argumento fundamental de Schumpeter é o de que a lei do valor só funciona se o trabalho for homogêneo e, além disso, se ele for o único fator de produção. Na presença de outros fatores as diferentes proporções entre os fatores causarão diferenças entre preços e valores.

Quanto à fraca performance de Marx no que diz respeito à questão do dinheiro quando comparado a Ricardo, uma digressão se faz necessária. Afinal, não é o próprio Marx que diz que a derivação do dinheiro é uma de suas principais descobertas? Por que então Scumpeter eleva a teoria do dinheiro de Ricardo acima da teoria de Marx se sabemos das limitações da teoria do dinheiro de Ricardo?

Notemos as limitações. Primeiro, o dinheiro para Ricardo se apresenta como mero instrumento de troca. O dinheiro na sua concepção não tem valor de uso e, portanto, é abandonado em troca de mercadorias. Com isso Ricardo deriva a idéia de que não pode haver superprodução de mercadorias, apenas superprodução parcial caracterizada como um saldo final correspondente a excessos setoriais de oferta. Ou seja, Ricardo não leva em consideração a possibilidade de que à venda não se siga imediatamente uma compra e, portanto, a possibilidade de superprodução generalizada. Dessa forma, a sua teoria do dinheiro conduz à lei de Say.

A segunda limitação diz respeito à cisão conceitual entre preço determinado pela quantidade de trabalho e nível de preços determinado pela quantidade de dinheiro. Reside aqui o interesse de Schumpeter na teoria do dinheiro de Ricardo. Basta para isso recordar a importância que tem a variação do nível de preços na Teoria do Desenvolvimento Econômico: o distúrbio causado pela inovação no interior do fluxo circular se manifesta por uma mudança no nível de preços causada pelo impacto da criação de poder de compra pelos bancos para financiar a implementação daquelas inovações. A superioridade da teoria do di- 
nheiro de Ricardo é, em outras palavras, a superioridade de sua teoria do desenvolvimento econômico!

\section{A mercadoria força de trabalho}

A apresentação da teoria da mais valia é muito confusa. Define a força de trabalho como um estoque de trabalho potencial do qual o capitalista compra uma parte. Mas isso é impossível! Primeiro porque o estoque de trabalho não existe em nenhuma quantidade pré-determinada. O que existe numa quantidade pré-determinada é a jornada de trabalho. E mesmo numa jornada de duração definida, a quantidade de trabalho que se pode extrair da força de trabalho varia de acordo com a intensidade do trabalho. O estoque total de trabalho potencial não está na força de trabalho, mas no número de horas de uma jornada de trabalho convencional. Ademais, se o capitalista compra somente uma parte do estoque potencial de trabalho usufruirá somente uma parte. Schumpeter parece ser presa da não distinção de Ricardo entre valor do trabalho e valor da força de trabalho. Para Marx valor de uso e valor são propriedades que advém de origens diferentes. $\mathrm{O}$ valor de uso advém das propriedades materiais da mercadoria; o valor advém da propriedade social da mercadoria de ser valor de uso produzido para a venda. A grande objeção de Schumpeter à teoria de Marx é a de que a força de trabalho não é produzida como resultado de um cálculo racional como o são as outras mercadorias. Mas o que caracteriza a mercadoria não é o fato de ser produto de um cálculo racional, mas sim o fato de forçar sobre o produtor individual uma adequação ao tempo de trabalho socialmente necessário, condição para que não forneça mais trabalho por menos. No capitalismo o excesso de população relativamente à capacidade de emprego do capital faz com que a força de trabalho tenda a receber sistematicamente menos do que o custo de sua reprodução: isso não a faz menos mercadoria; apenas uma mercadoria sobre a qual oferta e demanda operam de uma forma peculiar.

A definição de força de trabalho como estoque potencial de trabalho é muito problemática. Essa definição deixa de fora necessariamente a parte do custo de reprodução da força de trabalho que se refere à reprodução da força de trabalho enquanto classe, ou seja, a preparação de novos elementos da classe trabalhadora no âmbito da família. Comete o erro de colocar no custo da força de trabalho corrente o custo de sua preparação. ${ }^{9}$ Acontece que o trabalhador já foi preparado pela família na qual cresceu. Esse custo entrou no valor da força de trabalho de cuja

9 "Time it takes to rear, feed, clothe and house the labor" $(: 26)$ 
família resultou a força de trabalho atual. Esse é um aspecto importante para entender porque força de trabalho mais qualificada tem salários maiores.

De fato, nos rascunhos preparatórios d'O Capital conhecido como os Grundrisse, há uma sugestão interessante para uma possível compreensão dos diferenciais de salário de acordo com a qualificação: a formação dos novos elementos de cada sub-classe da força de trabalho necessitam valores de uso que encarecem a força de trabalho matriz. Se o salário é incompatível com esses custos mais elevados não haverá formação de novos elementos de cada sub-classe de trabalhadores. A escassez explica o aumento do salário do trabalhador matriz, mas não explica porque ele tem que ser mais alto. A explicação para o nível mais alto dos salários de acordo com o nível da qualificação se relaciona ao mais alto nível de custos de formação dos novos elementos de cada sub-classe de qualificação.

A definição de força de trabalho como estoque de trabalho potencial e, em seguida, o valor da força de trabalho como valor de uma parte desse estoque, é extremamente confusa. Aqui parece que Schumpeter optou por um meio mais obscuro de apresentação para melhor mostrar o fracasso da teoria de Marx. Comparando o regime assalariado capitalista com o escravismo Schumpeter diz: "O que o empregador do trabalhador livre compra não é, como no caso da escravidão, o próprio trabalhador, mas sim uma quota parte do trabalho potencial total" (p.26). Marx, porém, é claro a esse respeito: não se compra o trabalho porque o trabalho não é mercadoria; o trabalho é o usufruto da mercadoria força de trabalho. Portanto, não se pode comprar uma parte do fundo de trabalho potencial existente na força de trabalho.

De qualquer modo o valor das mercadorias se determina pelo tempo de trabalho socialmente necessário. Enquanto no caso das mercadorias ordinárias esse valor é determinado diretamente, no caso da força de trabalho ele se determina indiretamente pelo tempo de trabalho socialmente necessário para produzir as mercadorias que fazem parte da cesta real de consumo da força de trabalho, cesta esse que varia de país a país e que muda de acordo com o grau de produtividade e da divisão social do trabalho ao longo do tempo.

O valor de uso da força de trabalho é a própria capacidade de trabalho. O capitalista adquire, portanto, a capacidade de trabalho ao comprar a força de trabalho. Mas ele não paga a capacidade de trabalho, mas sim o custo de sua reprodução. ${ }^{10}$ 
Ao contrário do que diz Schumpeter, o capitalista não compra uma parte do trabalho potencial, mas sim a capacidade de trabalho a ser usufruída durante uma jornada mais ou menos longa. Paga o custo de sua manutenção e reprodução, custo esse que deve representar apenas uma parte do trabalho total executado durante a jornada. ${ }^{11}$

A apresentação de Schumpeter representa uma regressão em relação à apresentação do próprio Marx, pois oscila, por um lado, definindo estoque potencial de trabalho quantitativamente, por outro, qualitativamente como capacidade de trabalho.

\section{A teoria da mais valia}

Para mostrar que a teoria da mais valia é incongruente Schumpeter aplica a teoria neoclássica: se existem ganhos de "exploração" deve ser porque a produtividade marginal do trabalho está acima do salário. Os capitalistas expandirão a produção fazendo com que o salário aumente até o ponto no qual o salário se equipare à produtividade marginal do trabalho. Na verdade sobem os salários e cai a produtividade marginal ao mesmo tempo. Mas isso não constitui uma crítica, mas sim a apresentação de uma teoria alternativa na qual o trabalho contribui para o valor do produto exatamente o salário que recebe.

No contexto da teoria de Marx existem três forças que impedem com que os salários subam a ponto de eliminar toda a mais valia. ${ }^{12} \mathrm{~A}$ primeira é o fato de que o ritmo de acumulação é a variável que regula a variação dos salários, o que significa que a mesma causa que faz aumentar os salários é responsável pela sua redução quando os salários aumentam. Esta força está absolutamente alinhada à descoberta científica de Ricardo de que salários e lucros são inversamente proporcionais.

A segunda força é o aumento da composição técnica do capital, ou da composição de valor que reflete a composição técnica, razão que Marx denominou de composição orgânica. O aumento da composição orgânica cria uma força de trabalho disponível independentemente do crescimento vegetativo da população trabalhadora. Aqui Marx e Ricardo divergem pois para Ricardo o capital economizado em salários seria empregado na contratação de mais trabalhadores. ${ }^{13}$

11 "If one day's work were necessary in order to keep one worker alive for one day, then capital would not exist"(idem:324).

12 Apesar de que de um modo algo diferente, as duas primeiras causas foram observadas anteriormente por Elliot (1980:51).

13 O que é impossível pois parte desse montante deveria ser utilizado para a compra de meios de produção para os trabalhadores contratados. 
A terceira força se baseia na existência de formas do exército industrial de reserva das quais o capitalismo pode se valer em momentos de rápida acumulação de capital sem que sua absorção provoque o aumento dos salários.

A seqüência do raciocínio é digna de nota: dado que a mais valia não pode existir no equilíbrio neoclássico, pode existir em Marx porque nele o equilíbrio nunca se estabelece em virtude do fato de que as constantes inovações, seja de produto seja de processo, recriam constantemente as condições para a obtenção de lucros. Infelizmente, observa Schumpeter, a explicação satisfatória para esses lucros já não contém nada de especificamente marxista. Claro, pois esses lucros são precisamente as suas quase-rendas!

\section{Concorrência e tendência decrescente da taxa de lucro}

Finalmente, Schumpeter diz que a eliminação dos lucros de qualquer empresa pela concorrência é um substituto para a lei de tendência de queda da taxa de lucro já que essa eliminação é um análogo da idéia de que nenhum capital constante pode gerar excedente (sic! p.33). Não precisamos da teoria da queda da taxa de lucro porque a teoria neoclássica dá conta da eliminação do lucro econômico. Aqui a crítica à teoria de Marx se confunde novamente com a apresentação da teoria neoclássica, mas agora com um perfil inédito: substitui uma tendência que vale para o capital agregado por uma "tendência" de eliminação do lucro extraordinário pela concorrência.

Ora, em Marx a eliminação do lucro extraordinário pela concorrência é precisamente o mecanismo pelo qual a taxa de lucro efetua sua tendência declinante. Não se trata de dois fenômenos alternativos, mas sim de dois fenômenos conectados entre si por um vínculo causal: a generalização do método mais intensivo de capital constante faz cair os preços ao nível do valor individual associado àquele método. O lucro extraordinário desaparece ficando no seu rastro um capital de maior composição orgânica e menor taxa de lucro, coeteris paribus. ${ }^{14}$ 


\section{Inventário de erros e conclusão}

Schumpeter comete inúmeros equívocos de interpretação na sua leitura de Marx. Enumeramos abaixo alguns deles, for the record, antes de concluir o artigo.

1. A respeito da teoria da concentração do capital ele diz que a teoria de Marx se reduz à idéia de que "a batalha da concorrência se dá através do barateamento das mercadorias”. Essa citação aparece na análise do processo de centralização de capitais que Schumpeter parece misturar com o processo de concentração de capital.

2. Afirma que a utilização dos lucros é praticamente o único método que Marx aponta como forma de financiar a adoção de novas tecnologias. Na verdade, no contexto da teoria de Marx não pode ser o único método já que a depreciação moral dos equipamentos e maquinários que decorre das inovações técnicas requer necessariamente a complementação do fundo de depreciação - por definição incompleto - através do recurso ao crédito.

3. Identifica a causa da tendência de queda da taxa de lucro com o relativo aumento de capital constante nas indústrias que produzem bens salário. Por que faz isso? Seria talvez porque nesse caso o preço desses bens se elevaria acima do valor causando um aumento do preço da força de trabalho e conseqüentemente uma diminuição dos lucros. Não há nenhum motivo pelo qual a composição orgânica do capital nesses ramos deva se elevar mais do que a média da economia. O argumento de Marx não se relaciona especificamente ao aumento da composição do capital nas indústrias que produzem meios de subsistência. A composição orgânica do capital é resultado de uma média ponderada de todos os setores da economia. Qualquer aumento, em qualquer indústria, afeta a composição orgânica proporcionalmente ao seu peso na economia.

4. Substitui a tendência de queda da taxa de lucro pelo fenômeno de eliminação do lucro extraordinário. Em Marx sempre que o lucro extraordinário é obtido através da aplicação de métodos de produção mais intensivos de capital constante, a eliminação do lucro extraordinário faz com que a taxa de lucro reflita a nova e mais alta composição orgânica do capital. A eliminação do lucro extraordinário é o fenômeno de generalização do uso do método mais intensivo em capital constante. Por isso, eliminação do lucro extraordinário e tendência de queda não são fenômenos substituíveis entre si, mas ao contrário guardam uma relação de causa e efeito.

5. A definição de força de trabalho como estoque de trabalho potencial inviabiliza a compreensão da força de trabalho como mercadoria já 
que implica um intercâmbio desigual. A troca de mercadorias pelo seu valor e a exploração da força de trabalho se baseiam na existência da mercadoria força de trabalho e na separação entre o que determina o seu custo, de um lado, e o quanto ela é forçada a trabalhar, por outro.

6. A contínua busca por lucro extraordinário contradiz a teoria da equalização da taxa de lucro entre indústrias já que representa o próprio movimento de diferenciação de taxas de lucro, movimento esse contínuo. Ora, se não houvesse um movimento de diferenciação, o movimento de equalização seria assintótico e se exauriria mais cedo ou mais tarde. Não há nada ilógico na relação entre diferenciação de taxas de lucro e movimento de equalização.

7. A idéia de que a existência de mais valia faria com que as empresas incrementassem o investimento até o ponto no qual o aumento dos salários anulassem toda e qualquer mais valia é uma aplicação da teoria neoclássica do equilíbrio de concorrência perfeita na qual as firmas são infinitamente pequenas e podem produzir o quanto desejarem, são tomadoras de preço já que o preço é dado pelo mercado, e assim vai.

O estudo, explicitação, desenvolvimento e aplicação empírica da teoria de Marx só pode ser obra dos próprios marxistas. Cabe a eles, no entanto, a tarefa de fazer esse trabalho melhor do que aqueles que desfiguram a sua teoria sistematicamente.

\section{Referências}

CÂMARA, N. \& CORDEIRO, G. \& CIPOLLA, F. (2000). "Capital fixo, lucro e as contradições da teoria do valor de Ricardo". UFPR, textos PET-Economia, mimeo.

CIPOLLA, F.P. "The concept of market value: a critical note on Itoh's theory". Review of Radical Political Economics, 40(2) (prelo).

ELLIOT, J. E. (1980). "Marx and Schumpeter on Capitalism's Creative Destruction: a Comparative Restatement”. The Quarterly Journal of Economics, pp. 45-68.

GIUSSANI, P. "Ricardo and Marx". In BOTTOMORE, Tom (org.) A Dictionary of Marxist Thought. Cambridge: Harvard University Press, pp. 428-430.

MANKIW, N. G. (1992). Macroeconomics. New York: Worth Publishers.

KEYNES, J. M. (1964). The General Theory of Employment, Interest, and Money. New York \& London: Harvest/HBJ.

MARX, K. (1971). Theories of Surplus Value, tomo II. Moscou: Progress Publishers.

MARX, K. (1973). Grundrisse - Foundations of the Critique of Political Economy. 
CIPOLLA, F. Valor e concorrência em Marx e os vários equívocos da crítica...

London: Penguin Books.

RICARDO, D. (1982). On the Principles of Political Economy and Taxation. London - New York: Cambridge University Press.

ROBERTS, J. (1987). "Perfectly and imperfectly competitive markets". In EATWELL, Milgate e NEWMAN (org.), The New Palgrave: a Dictionary of Economics. Londres: The MacMillan Press, pp. 837-841.

SAMUELSON, P. \& NORDHAUS, W. (1985). Economics. New York: McGrawHill Book Company.

SCHUMPETER, J. A. (1994). Capitalism, Socialism and Democracy. London e New York: Routledge. 